\title{
Effect of Giving Nano Calcium Phosphate Diet on Mineral Content and Function Groups of Ovariectomy Tibia Rats
}

\author{
Neng Nenden Mulyaningsih ${ }^{1,2}$, Ariadne Laksmidevi Juwono ${ }^{1 *}$, Djarwani Soeharso Soejoko ${ }^{1}$ and Dewi Apri \\ Astuti $^{3}$ \\ ${ }^{1}$ Department of Physics, Faculty of Mathematics and Natural Sciences (FMIPA), Universitas Indonesia \\ Depok 16424, Indonesia \\ ${ }^{2}$ Department of Physics Education, Faculty of Mathematics and Natural Sciences, Universitas Indraprasta PGRI Jakarta \\ Jakarta 12530, Indonesia \\ ${ }^{3}$ Department of Nutrition and Feed Technology, Faculty of Animal Sciences, Bogor Agricultural University \\ Bogor 16680, Indonesia \\ ${ }^{*}$ Corresponding author's email: Ariadne.laksmidevi [AT] ui.ac.id
}

\begin{abstract}
Lack of calcium and phosphorus minerals in bones can cause decreased bone density, bone becomes brittle and at risk of osteoporosis. The purpose of this study was to analyze changes in mineral levels and functional groups in tibia osteoporosis because of ovariectomy and were treated with a nano-calcium phosphate diet. In this research, dietary formulations containing nano-calcium phosphate made. Diets given to animal models of osteoporosis rats caused by ovariectomy with the aim to balance the mineral content in the rats tibia. Dietary formulations were made of 3 types based on their calcium content, namely the first diet (D1), the second diet (D2) and the third diet (D3) each having a total calcium content of 1.0x, 1.5x and 2.0x normal body needs. Characterization and analysis of mineral content in the tibia bone using Atomic Absorption Spectroscopy (AAS) and Ultraviolet-Visible $(U V-v i s)$, while the characterization and analysis of functional groups with Fourier Transform Infrared Spectroscopy (FTIR). Based on the data obtained, ovariectomy rats showed signs of osteoporosis with decreased levels of calcium in the tibia and a decrease in phosphate ion function groups at 9 weeks since ovariectomy. The results of dietary treatment showed that postovariectomy osteoporosis rats fed a diet with a total calcium content of $1.5 x$ normal body needs (D2) and gave more effective and efficient results compared to diets containing 1.0x (D1) and 2.0x (D3) total calcium normal body needs.
\end{abstract}

Keywords— nano-calcium phosphate, ovariectomy, osteoporosis, tibia mineral, functional groups

\section{INTRODUCTION}

Osteoporosis is a metabolic disease that is widespread in the world [1,2,3,4,5]. Osteoporosis is an abnormality in bone in the form of a decrease in bone mass [6,7,8]. Osteoporosis can occur both in men and women especially those who have entered old age $[9,10,11]$. Women who enters the menopausal mass are more risky of osteoporosis because of an imbalance of the hormone estrogen $[12,13,14,15]$.

In addition to age, hormonal problems can occur because of ovarian cysts or surgical removal of the uterus (ovariectomy). Several previous researchers examined the effects of ovariectomy (OVX), including causing morphometric and densitometric changes in the tibia bone [16], being overweight [17], and bone becomes porous [18]. Other researchers also have shown that OVX causes an increase in cortical bone blood vessel porosity and decreased bone mineral [19]. All things that arise because of OVX contribute to bone fragility during the process leading to osteoporosis. Although there have been many studies that discuss the effects of OVX, but no one has explained the time until the onset of osteoporosis. In this study observed and analyzed a decrease in minerals gradually every 2 weeks until the occurrence of osteoporosis. The observation time is chosen every 2 weeks because the estrous cycle period in rats lasted for 2 weeks [20].

Some techniques for treating osteoporosis include bisphosphonates [21,22,23], alendronate or odanacatib [24], parathyroid hormone and abaloparatide [25]. These drugs have recently been known causing digestive disorders, esophagus, hypocalcemia, inflammation of the eyes, bone and joint pain, femur fractures, hypercalciuria, malignant bone tumors and damage to the jawbone, so the use of these drugs is still pro and counter. In addition, there are also 
researchers who use herbal ingredients used in osteoporosis treatment. Some of them use sage, rosemary, thyme [26], roots and leaves of Marantodes pumilum [27]. However, the use of herbal ingredients has several limitations including requiring longer time to obtain medicinal properties, raw materials have not been standardized and are hygroscopic and volumines, have not been clinically tested and are easily contaminated by various types of microorganisms. Therefore, in this study selected postovariectomy osteoporosis recovery therapy by giving nano-calcium phosphate diet. In accordance with the estrous cycle in rats, the effect of giving a nano-calcium phosphate diet is also observed periodically every 2 weeks. The aim is to find out the intensity of the mineral rise in the tibia bone, to obtain bone mineral levels as in normal bone conditions at the most optimal time.

The renewal of this research is the analysis during the stage towards osteoporosis and the recovery phase of osteoporosis carried out in stages. In addition, calcium phosphate is added to the nano-sized diet. Nano-sized particles are known to have a wider surface area, so they will be more easily absorbed by the body [28].

\section{EXPERIMENTAL PROCEDURE}

\subsection{Preparation of Animal Model and Sample Collection}

There were 110 white rats (Rattus norvegicus) kept from the age of 6 weeks, 90 were ovariectomized and the remaining (15) were not ovovated as controls. The use of animal models of rats and treatment of rats both ovariectomy and euthanasia had been approved by the Health Research Ethics Committee of the Faculty of Medicine, University of Indonesia, Cipto Mangunkusumo Hospital. The bone that is characterized and analyzed was the cortical portion of the tibia bone. The study was conducted in two stages, namely the first stage of ovariectomy rats and given a non-nano diet (standard diet), this stage is called the stage towards osteoporosis. The second stage was the rats that had already in the condition of osteoporosis obtained from the first stage, then given a nano-calcium phosphate diet, this stage is called the stage of diet treatment. The distribution of the use of rats was presented in Table 1.

Table 1: Treatment groups

\begin{tabular}{|c|c|c|c|c|c|}
\hline \multirow[t]{2}{*}{ Stage } & \multirow[t]{2}{*}{ Age (week) } & \multirow[t]{2}{*}{ Description } & \multicolumn{3}{|c|}{ Tibia Sample Code } \\
\hline & & & & Abbreviation & \\
\hline \multirow{2}{*}{ 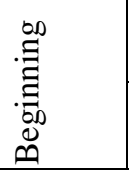 } & 6 & $\begin{array}{l}\text { - Weaning Age } \\
\text { - Rats start to be maintained }\end{array}$ & - & - & - \\
\hline & 12 & $\begin{array}{l}\text { - Purbety Age } \\
\text { - Ovariectomy rats }\end{array}$ & - & - & - \\
\hline \multicolumn{6}{|c|}{ One week Adaptation } \\
\hline \multirow{2}{*}{ 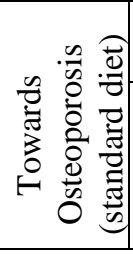 } & 13 & $\begin{array}{l}\text { Collection of control tibia rats bone } \\
\text { (non-OVX) }\end{array}$ & & TK & \\
\hline & $\begin{array}{l}15 \\
17 \\
19 \\
21 \\
\end{array}$ & $\begin{array}{l}\text { Collection of rats tibia bone stage to } \\
\text { osteoporosis }\end{array}$ & & $\begin{array}{l}\text { TO3 } \\
\text { TO5 } \\
\text { TO7 } \\
\text { TO9 } \\
\end{array}$ & \\
\hline \multicolumn{6}{|c|}{ Adaptation to 6 weeks diet treatment } \\
\hline 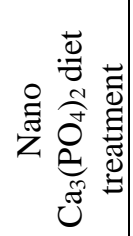 & $\begin{array}{l}27 \\
29 \\
31 \\
33 \\
40\end{array}$ & $\begin{array}{l}\text { Collection of diet treatment rats tibia } \\
\text { bone }\end{array}$ & $\begin{array}{c}\text { TDA6 } \\
\text { TDA8 } \\
\text { TDA10 } \\
\text { TDA12 } \\
\text { TDA19 }\end{array}$ & $\begin{array}{c}\text { TDB6 } \\
\text { TDB8 } \\
\text { TDB10 } \\
\text { TDB12 } \\
\text { TDB19 }\end{array}$ & $\begin{array}{r}\text { TDC6 } \\
\text { TDC8 } 8 \\
\text { TDC10 } \\
\text { TDC12 } \\
\text { TDC19 }\end{array}$ \\
\hline
\end{tabular}

TK: Control rats tibia bone (not ovariectomy)

TO3-TO9: Tibia bone from 3-9 weeks rats since ovariectomy

TDA6-TDA19: Osteoporosis tibia bone given D1 diet in 6-19 weeks

TDB6-TDB19: Osteporosis tibia bone given D2 diet in 6-19 weeks

TDC6-TDC19: Osteporosis tibia bone given D3 diet in 6-19 weeks

\subsection{Creation of Standard Diet and Nano-Calcium Phosphate Diet}

A standard diet obtained from commercial products with dietary composition consisting of protein, fat, fiber, ash, calcium and phosphorus [29]. A standard diet was given to rats that were kept during the stages leading to osteoporosis. The nano-calcium phosphate diet was made with a diet modification formulated by Astuti [30]. The main ingredients for making nano-calcium phosphate diets were rice flour, casein, corn oil, glucose, DL-methionin, carboxymethyl cellulose 
(CMC), calcium phosphate $\left(\mathrm{Ca}_{3}\left(\mathrm{PO}_{4}\right)_{2}\right)$, vitamin mix, and $\mathrm{NaCl}$. Calcium phosphate used in the manufacture of diets was a commercial calcium phosphate product from Merck with a catalog number 804604 and made into nano-size according to the modified Mulyaningsih et al.[31] and Cabeza et al. [32] methods. Calcium phosphate that milled for 30 hours and measuring $8.17 \mathrm{~nm}$ was added to the main ingredient of the diet and made 3 types, namely the first diet (D1) containing $0.40 \%$ calcium (total calcium content of $1.0 x$ normal body needs), the second diet (D2) containing $0.62 \%$ calcium content (total calcium content of $1.5 \mathrm{x}$ normal body needs) and the third diet (D3) containing calcium $0.99 \%$ (total calcium content of 2.0x normal body needs). Nano calcium phosphate diet was given to rats that were kept at the stage of dietary treatment.

\subsection{Characterization and Analysis}

Bone samples that had been cleaned then soaked with a solution of hydraziniumhydroxid $\left(100 \% \mathrm{~N}_{2} \mathrm{H}_{5} \mathrm{OH}\right)$ for 1 week, continued soaking with $70 \%$ alcohol for 1 hour and rinsed with distilled water three times, and dried at $60{ }^{\circ} \mathrm{C}$ for 24 hours, then crushed until smooth and repeated soaking with a solution of hydraziniumhydroxid $\left(100 \% \mathrm{~N}_{2} \mathrm{H}_{5} \mathrm{OH}\right)$ for 1 week, followed by soaking with $70 \%$ alcohol for 1 hour, and rinsed with distilled water three times, and dried again at 60 ${ }^{\circ} \mathrm{C}$ for 24 hours referring to the modified Oetama method [33]. The tibia bone sample was calculated for its calcium and magnesium levels using the atomic absorption spectrometry (AAS) method, while the phosphorus mineral using ultraviolet-visible (UV - vis) spectroscopy.

The procedure for testing bone mineral content using AAS is the dry ashing method based on the Association of Analytical Communities [34]. Bone samples were placed on a porcelain cup and then burnt on a furnace for 4 hours at a temperature of $700{ }^{\circ} \mathrm{C}$. After that it was removed and cooled to the excitator. After the ashing was complete, it was weighed of $0.1 \mathrm{~g}$ on a porcelain cup. Next $10 \% \mathrm{HCl}$ was added by $10 \mathrm{~mL}$ and heated on a hot plate until the volume decreased to $1 / 4$ cup then $10 \% \mathrm{HCl}$ was added as much as $10 \mathrm{~mL}$ to be heated again on the hot plate until the volume reduced to $1 / 4$ cup. Samples were transferred to a measuring flask and added distilled water to $50 \mathrm{~mL}$, then filtered with whattman 41 paper. Clear samples were ready to be measured with AAS.

The procedure for the characterization of phosphorus minerals by UV - vis is bone samples, blanks and standards of $10 \mu \mathrm{L}$ was put in a test tube then $1000 \mu \mathrm{l}$ enzymes- 1 in the form of solvents were then vortex for 10 seconds and incubated for 5 minutes, added $250 \mu$ of enzyme-2. Then vortex again for 10 seconds was measured using a reagent kit and then read the absorbance at a wave length of 570-580 nm using a UV - vis spectrophotometer.

Fourier Transform Infrared Spectroscopy (FTIR) characterization was carried out to identify functional groups contained in tibia bone samples. In this study the use of FTIR is intended to identify the presence of various phases of calcium compounds by knowing the phosphate, carbonate and hydroxyl ion groups and crystallinity estimates. Bone samples to be tested were crushed with a mortar until smooth and then separated by $2.5 \mathrm{mg}$ and added $250 \mathrm{mg}$ of potassium bromide $(\mathrm{KBr})$, then homogenized using mortar and pestle. After being homogeneous, the sample was molded into pellets with pressures up to 8 tons then analyzed. The range of infrared energy used in measurements was expressed in wavenumber from $400-4000 \mathrm{~cm}^{-1}$. The analysis was done by looking at the shape of the spectrum by looking at specific peaks that indicated the type of functional group that is owned by bone. The sample function groups were determined based on the absorption of the detected wavenumbers [35,36]. The crystallinity index was calculated based on the splitting function (SF), by adding up the height of the two anti-symmetric phosphate peaks (range of wavenumbers $603 \mathrm{~cm}^{-1}$ and $563 \mathrm{~cm}^{-1}$ ) and dividing the value by the height of the trough between the two peaks. All heights measured above the baseline are drawn from wavenumbers around $(780-495) \mathrm{cm}^{-1}$ [37]. The splitting function measurement technique is presented in Fig. 1.

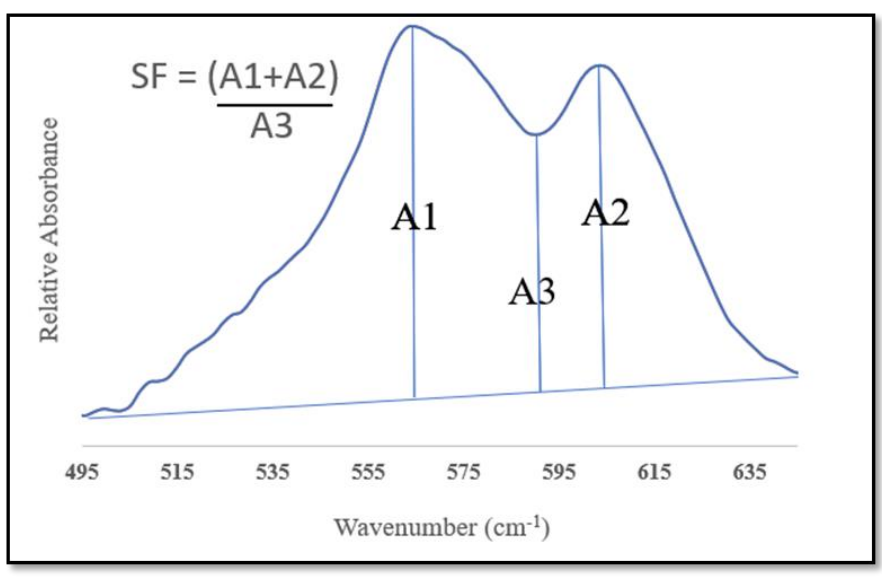

Figure 1: Splitting function (SF) calculation technique. 


\subsection{Statistics Analysis}

In this study there were 4 treatments and 5 replications in combination as follows:

DK: treatment of unovariectomized rats by administering a standard diet

D1: ovariectomy diet treatment by giving calcium phosphate diet 1.0x normal requirements

D2: ovariectomy diet treatment by giving calcium phosphate diet $1.5 \mathrm{x}$ normal requirements

D3: ovariectomy diet treatment by giving calcium phosphate diet 2.0x normal requirements

Analysis of the data used was an independent $\mathrm{T}$ test by comparing the results obtained from the data of DK with D1, DK with D2 and DK with D3 and it was also compared to dietary treatment data D1 with D2 and D2 with D3. P values $<0.05$ were considered statistically significant. Results were expressed as the mean \pm standard deviation.

\section{RESULTS AND DISCUSSION}

\subsection{Mineral Content in Tibia Bone}

Minerals measured in the tibia were calcium $(\mathrm{Ca})$, phosphorus $(\mathrm{P})$ and magnesium $(\mathrm{Mg})$. In the stage to osteoporosis, the mineral content of $\mathrm{Ca}$ and $\mathrm{P}$ in the tibia bone had a tendency to decrease (Fig. 2 and Fig. 3), except in the fifth week since ovariectomy, an increase in $\mathrm{Ca}$ and $\mathrm{P}$ minerals. The increase that occurred was not significant $(\mathrm{P}>$ 0.05), one of the factors causing the increase was the variety of rats used. The seventh and ninth weeks showed that $\mathrm{Ca}$ and $\mathrm{P}$ minerals were back down. The decrease in the mineral content of $\mathrm{Ca}$ and $\mathrm{P}$ in the ninth week was significantly different from the controls $(\mathrm{P}<0.05)$. The linear regression equation for the reduction of $\mathrm{Ca}$ and $\mathrm{P}$ had a $\mathrm{R}^{2}$ value of 0.87 (Fig. 2.b) and 0.82 (Fig. 3.b). Both of these values indicated that $\mathrm{Ca}$ and $\mathrm{P}$ decrease in time correlation.

The Mg content had a fluctuating value (Fig. 4). Three weeks after ovariectomy increased significantly $(\mathrm{P}<0.05)$. Five weeks after ovariectomy returned. The seventh and ninth weeks were respectively up and down but not significant $(\mathrm{P}>0.05)$. Therefore, the $\mathrm{Mg}$ content in the tibia bone cannot be predicted based on the time function. $\mathrm{R}^{2}$ value $=0.13$ (Fig. 4.b) showed that there was no strong relationship between Mg content and time. This happens because Mg can act as an inhibitor of bone.

Findings from rats had decreased mineral levels in their bones, especially $\mathrm{Ca}$ and $\mathrm{P}$ minerals. Minerals decreased gradually. Residual minerals in the minerals in osteoporotic bone occured in the ninth week since ovariectomy. In the ninth week, Ca mineral content was $17.40 \% \mathrm{w} / \mathrm{w}$ and P $1.09 \% \mathrm{w} / \mathrm{w}$. The results obtained support the results of previous studies stated that osteoporosis bone Ca mineral content caused by ovariectomy was $22.92 \% \mathrm{w} / \mathrm{w}$, whereas osteoporosis bone phosphorus content was $10.26 \% \mathrm{w} / \mathrm{w}$ [38]. The results obtained confirm that ovariectomized rats with osteoporosis were seen based on the mineral content of $\mathrm{Ca}$ and $\mathrm{P}$ that occurred at the ninth week.

Nano-calcium phosphate diet treatment, on average can increase the three types of minerals in the tibia bone. The mineral content of $\mathrm{Ca}$ and $\mathrm{P}$, the size returned to normal after giving a D2 or D3 diets for 19 weeks, but in the group of rats given the D1 diet and the value had not returned to normal as a control. Nano-calcium phosphate diet showed Ca increased with linear regression equation as in Fig. 2.c. The increase of $\mathrm{Ca}$ was correlated with time. Based on the linear regression equation, the administration of the D3 diet had the highest correlation with time compared to the D1 or D2 diets. Likewise, the effect of diet on the increase in P minerals showed a linear relationship with time (Fig. 3.c). During 19 weeks of administration of the nano-calcium phosphate diet, starting from the D1 to D3 diets showed a greater value of the mineral P deposited in the tibia bone compared to controls. This indicates the growth of bone crystals.

$\mathrm{Mg}$ in the tibia bone that had been treated with nano-calcium phosphate diet at the age of 40 weeks (19 weeks of dieting). It showed a higher value than the $\mathrm{Mg}$ content in the tibia control. This is in accordance with the nature of $\mathrm{Mg}$, which helps the absorption of $\mathrm{Ca}$ in the body, thus making bones strong and dense [39]. This condition showed that even though the mineral content of $\mathrm{Ca}$ and $\mathrm{P}$ is as normal as bone, the strength had not yet returned to normal. It is necessary to carry out further tests such as mechanical tests in the form of tensile tests or bone morphological observations with Scanning Electron Microscopy (SEM) or Transmission Electron Microscopy (TEM). 


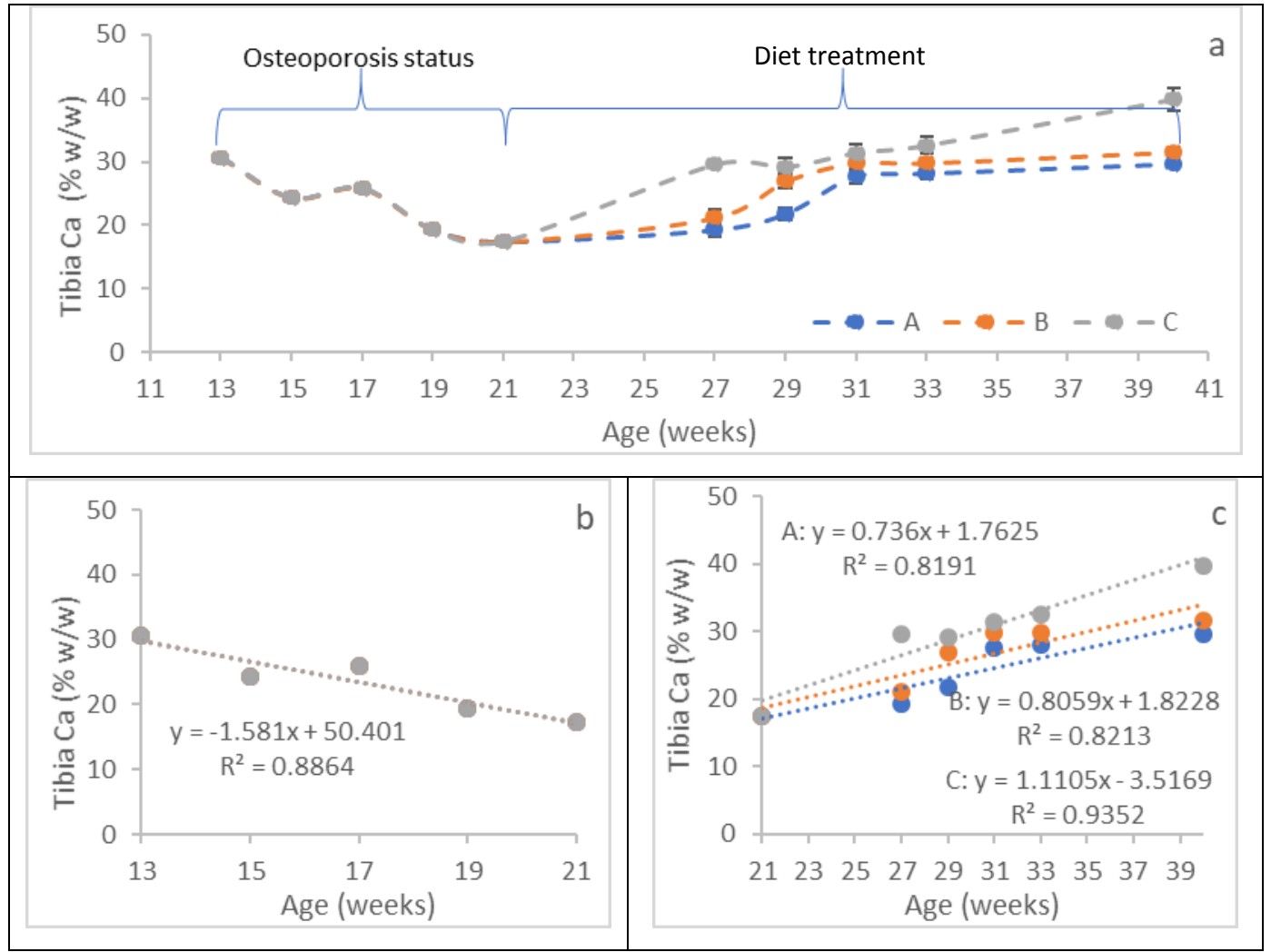

Figure 2: Average tibia calcium mineral content: a) full display, b) osteoporosis step and c) diet treatment step.

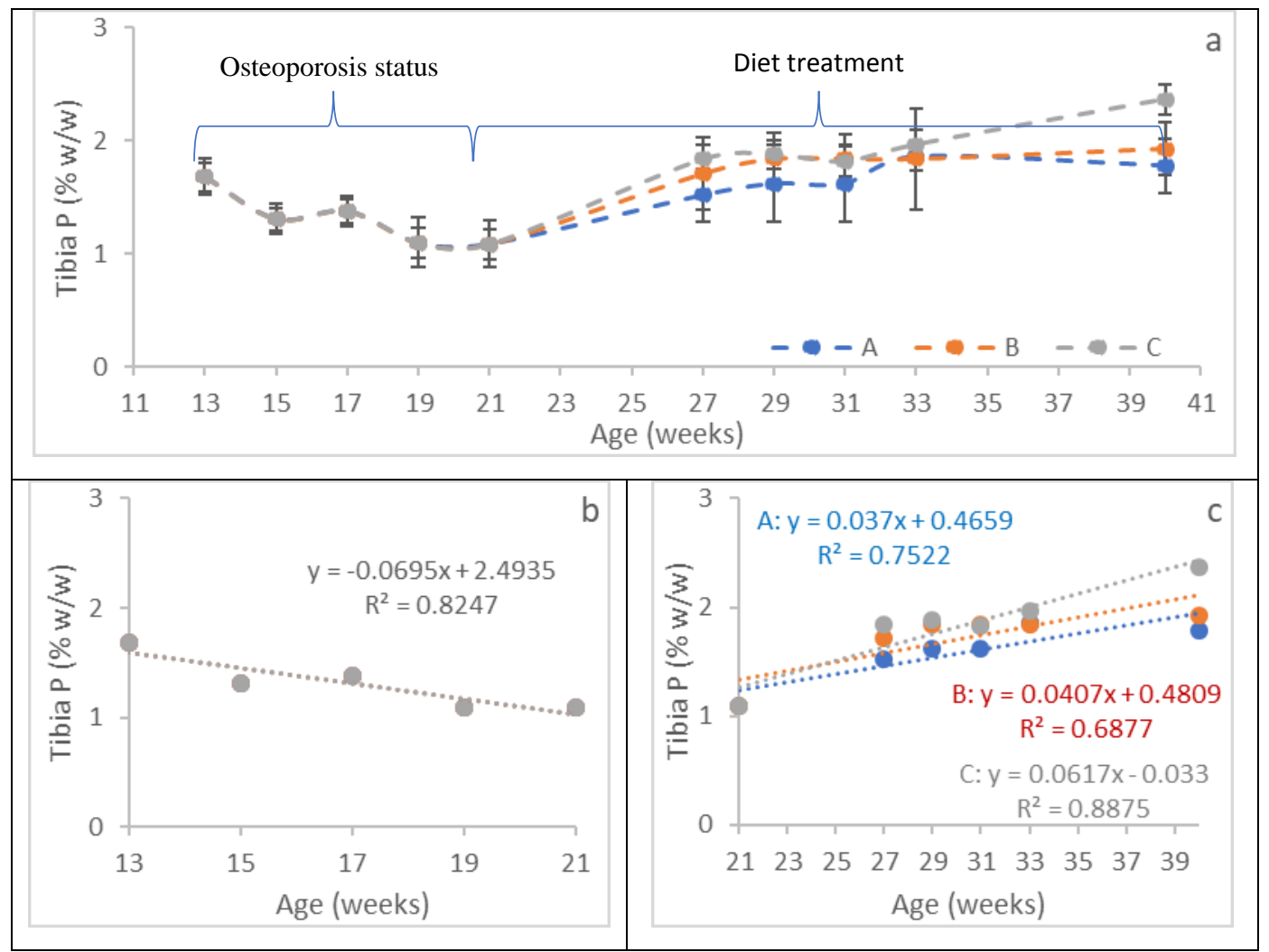

Figure 3: Average mineral content of tibia phosphor mineral, a) full display, b) osteoporosis step and c) diet treatment step. 


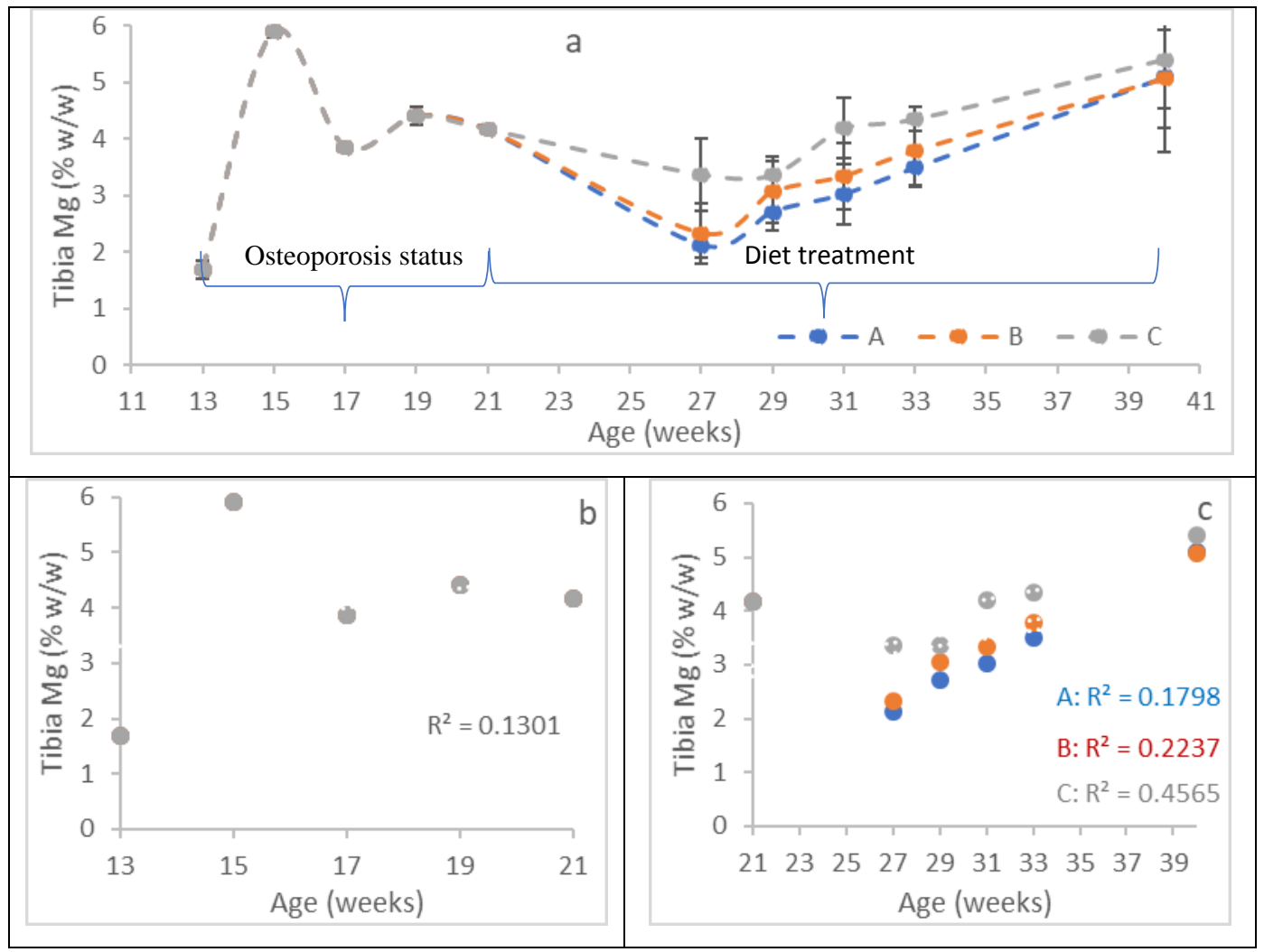

Figure 4: Average mineral content of tibia magnesium mineral, a) full display, b) osteoporosis step and c) diet treatment step.

\subsection{Typical Spectra of Phosphate Clusters}

Phosphate groups in the tibia were observed in two regions, namely wavenumbers of $495-645 \mathrm{~cm}^{-1}$ and $900-1200$ $\mathrm{cm}^{-1}$, respectively shown in Fig. 5 and Fig. 6. Phosphate groups in the range of wavenumbers $495-645 \mathrm{~cm}^{-1}$ had two maximum peaks at wavenumbers $569 \mathrm{~cm}^{-1}$ and $604 \mathrm{~cm}^{-1}$ that were phosphate groups with bending vibrations $\left(v_{4}\right)$. From the $v_{4}$ phosphate group with the splitting function (SF) value obtained as presented in Table 2.

Phosphate peak for groups of rats in the stage to osteoporosis showed a decrease in phosphate intensity (Fig. 5.a) and SF values (Table 2). From Fig. 5.a, it can be seen that the rats in the TO3 group to the TO9 group had almost the same pattern, namely the division of the ribbon in the phosphate group was getting shorter which indicated the presence of an amorphous phase. Amorphous phases that appeared indicate that the condition of the bones was more fragile. The shortened cleavage also indicates that the crystallinity index decreased, so that in the tibia there was a mixture of crystalline and amorphous phases, with the more dominating amorphous phase. This means that the tibia bone that had been ovariectomized had decreased strength. The biggest decrease occurred at the $9^{\text {th }}$ week after ovariectomy, because in the $9^{\text {th }}$ week the level of damage was higher than in the other groups. This level of damage is a sign of osteoporosis in the tibia.

In the group of rats fed the D1 diet (Fig. 5.b), the maximum peak of the phosphate group with fluctuating intensity was quantitatively supported by the fluctuating SF values and until 19 weeks of the diet the SF values were still under control. The maximum peak of the phosphate group of the group of rats fed the D2 and D3 diets for up to 19 weeks showed a more symmetrical peak shape (Fig. 5.c-d). It is Supported also by the SF value that was increasing along with the longer time of giving the diet. The tibia bone treated with diet D2, the SF value exceeded the control value at week 19, and the tibia bone treated with diet D3 showed the same SF value as the control at week 12 giving the diet. In the 19 th week, SF had greater value than the control value. The increasing value of SF showed the index of bone crystallinity increasing.

The phosphate group in wavenumber between $900-1200 \mathrm{~cm}^{-1}$ in the rats group at the stage towards osteoporosis, qualitatively decreased the typical peak of the phosphate at wavenumber $962 \mathrm{~cm}^{-1}$ that was a phosphate group with a vibrational streching symmetry $\left(v_{l}\right)$ mode. This phosphate group was an unstable phosphate group. In addition, there was also a typical peak of stable phosphate at wavenumber $1031 \mathrm{~cm}^{-1}$ with asymmetric streching vibration mode ( $\left.v_{3}\right)$ (Fig. 6.a). In the treatment of D1, D2 and D3 diets showed no significant difference, but from week 6 to week 19 giving the 
diet, showing the direction of bone repair, seen from the growth of phosphate groups that were sharper. Unstable phosphate groups appeared to grow back. This supports the results of mineral analysis that indicates the presence of phosphorus deposited in bone because of the administration of nano-calcium phosphate diet.

Table 2: Splitting function (SF) value of phosphate group $v_{4}$ FTIR spectra of tibia bone FTIR

\begin{tabular}{|c|c|c|c|c|}
\hline Sample Code & A1 & A2 & A3 & $\begin{array}{c}\mathrm{SF}= \\
(\mathrm{A} 1+\mathrm{A} 2) / \mathrm{A} 3\end{array}$ \\
\hline \multicolumn{5}{|c|}{ SF Group of Rats to Osteporosis } \\
\hline TK & 2.89 & 2.78 & 2.20 & 2.58 \\
\hline TO3 & 2.93 & 2.73 & 2.25 & 2.52 \\
\hline TO5 & 2.79 & 2.65 & 2.30 & 2.37 \\
\hline TO7 & 2.75 & 2.64 & 2.29 & 2.35 \\
\hline TO9 & 2.81 & 2.72 & 2.38 & 2.32 \\
\hline \multicolumn{5}{|c|}{ SF Group of Osteoporosis Rats Given A Diet } \\
\hline TDA6 & 1.98 & 2.24 & 1.83 & 2.31 \\
\hline TDA8 & 2.43 & 2.11 & 1.96 & 2.32 \\
\hline TDA10 & 2.64 & 2.23 & 2.11 & 2.31 \\
\hline TDA12 & 2.21 & 2.07 & 1.78 & 2.41 \\
\hline TDA19 & 2.22 & 2.12 & 1.82 & 2.38 \\
\hline \multicolumn{5}{|c|}{ SF Group of Osteoporosis Rats Given B Diet } \\
\hline TDB6 & 2.51 & 2.53 & 2.14 & 2.36 \\
\hline TDB8 & 2.49 & 2.38 & 2.00 & 2.44 \\
\hline TDB10 & 2.51 & 2.43 & 2.01 & 2.44 \\
\hline TDB12 & 2.53 & 2.46 & 2.00 & 2.50 \\
\hline TDB19 & 2.52 & 2.46 & 1.88 & 2.65 \\
\hline \multicolumn{5}{|c|}{ SF Group of Osteoporosis Rats Given C Diet } \\
\hline TDC6 & 2.34 & 2.53 & 2.06 & 2.36 \\
\hline TDC8 & 2.48 & 2.39 & 1.96 & 2.48 \\
\hline TDC10 & 2.48 & 2.37 & 1.92 & 2.53 \\
\hline TDC12 & 2.36 & 2.27 & 1.79 & 2.58 \\
\hline TDC19 & 2.35 & 2.33 & 1.74 & 2.69 \\
\hline
\end{tabular}

\subsection{Typical Spectra of Carbonate Cluster}

The carbonate group was observed in two areas of wavenumbers, namely between $700-950 \mathrm{~cm}^{-1}$ and $1300-1600 \mathrm{~cm}^{-}$ ${ }^{1}$, respectively shown in Fig. 7 and Fig. 8. In Fig. 7 there are two types of carbonate groups, namely carbonate $v_{2}$ in the range of wavenumber $873 \mathrm{~cm}^{-1}$ and carbonate $v_{4}$ in the range of wavenumber $719 \mathrm{~cm}^{-1}$. The carbonate group $v_{2}$ tended to be the same that was found for all groups. The $v_{4}$ carbonate group did not appear in all groups. In control rats $v_{4}$ carbonate groups were not found, whereas in the ovariectomized group of rats the presence of carbonate groups with higher intensity began from the $3^{\text {rd }}$ week since ovariectomy. This indicated that in the ovariectomy tibia more phosphate groups were replaced by carbonate groups (Fig. 7.a).

Likewise for carbonate groups in wavenumbers between $700-950 \mathrm{~cm}^{-1}$ for the diet treatment group (Fig. 7.b-d) showed that the carbonate group $v_{2}$ was present for each group and the carbonate group $v_{4}$ was increasingly disappearing. Nineteen weeks on the administration of the nano-calcium phosphate diet, the $v_{4}$ carbonate group again disappeared. The area of carbonate groups in this region was strongly influenced by $\mathrm{HPO}_{4}{ }^{2-}$ concentration [40]. No appearance of the carbonate group indicated that the phosphate group started to grow back. 


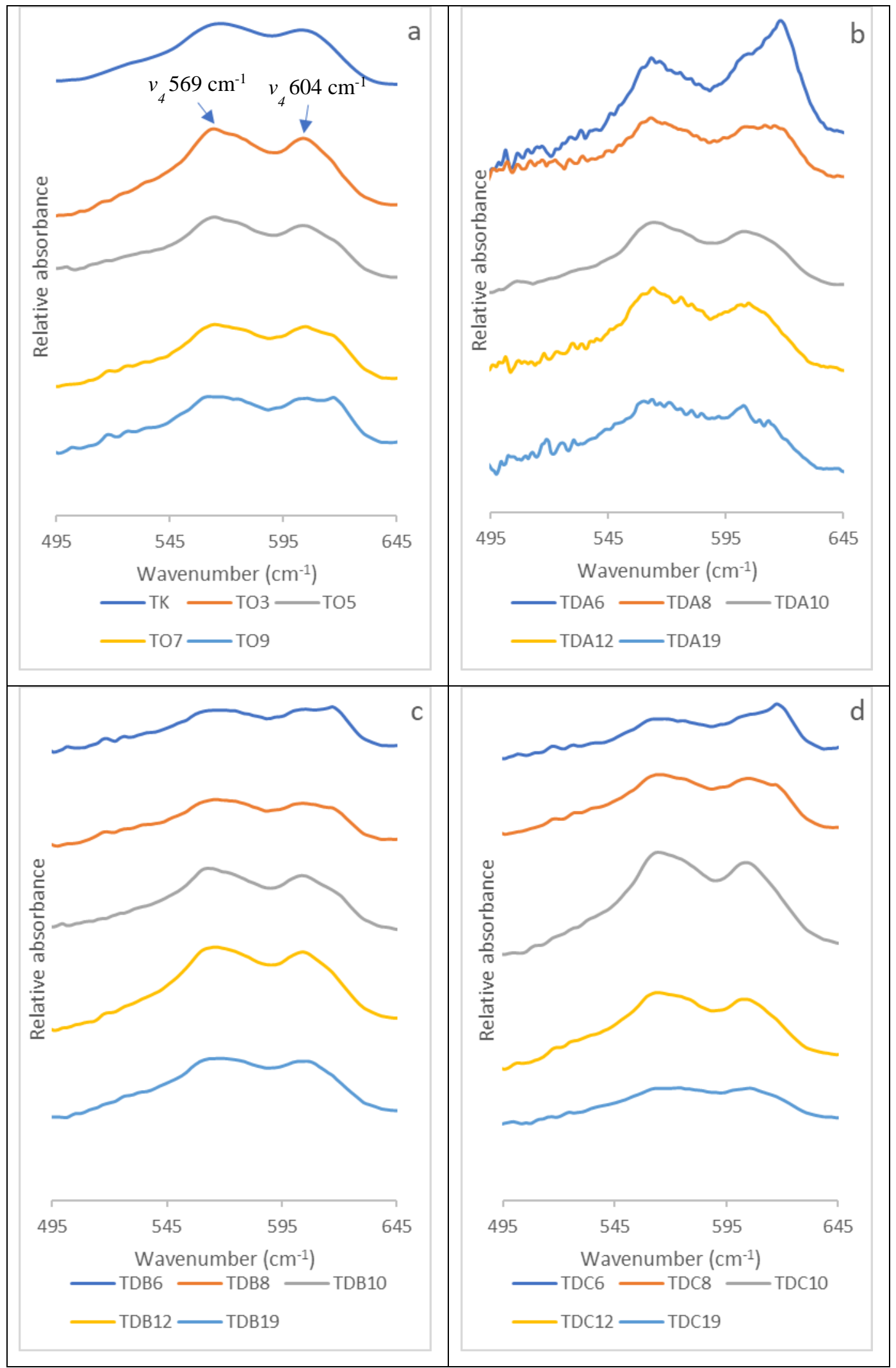

Figure 5: Footage of FTIR results for the phosphate group from tibia at $495-645 \mathrm{~cm}^{-1}$ wavenumber. 


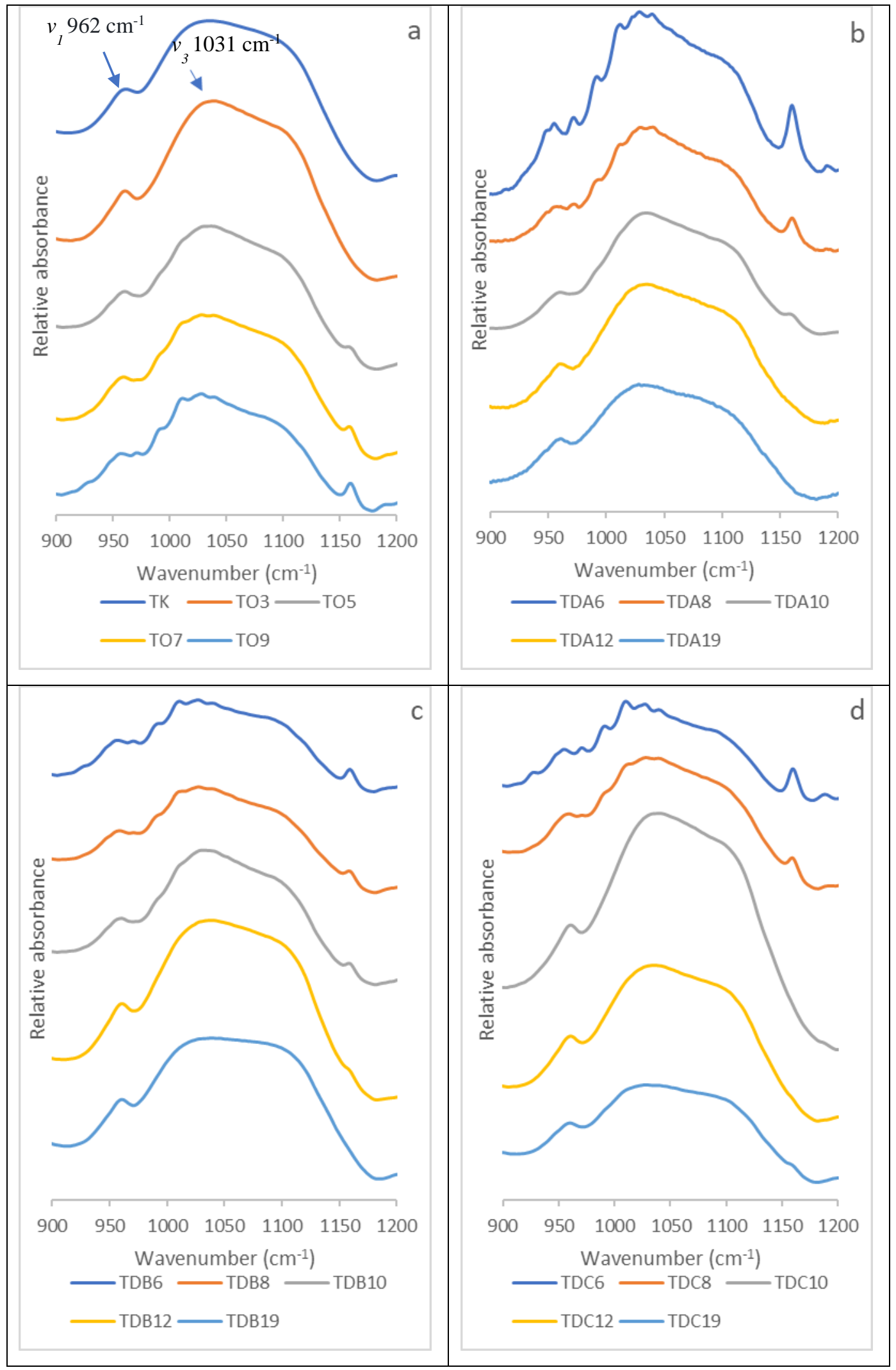

Figure 6: Footage of FTIR results for the phosphate group from tibia at $900-1200 \mathrm{~cm}^{-1}$ wavenumber. 


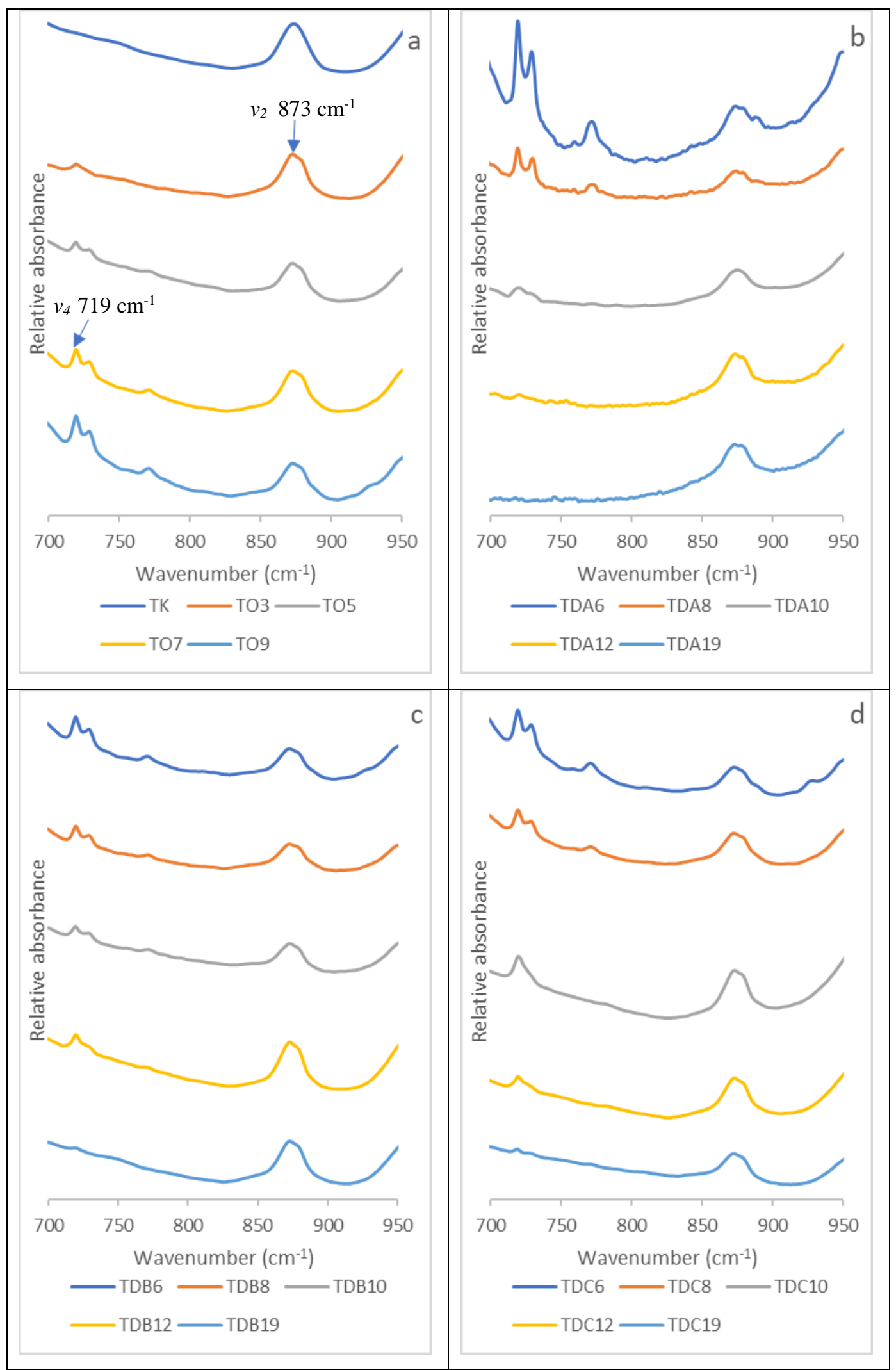

Figure 7: Footage of FTIR results for the carbonate group from tibia at $700-950 \mathrm{~cm}^{-1}$ wavenumber.

Fig. 8 shows a sample of the tibia bone FTIR results for the carbonate group at wavenumber between $1300-1600 \mathrm{~cm}^{-1}$. The carbonate group at wavenumber between 1300-1600 $\mathrm{cm}^{-1}$ consisted of several different peaks. The carbonate peak at wavenumber $1450-1500 \mathrm{~cm}^{-1}$ was a type A apatite, which is a carbonate group that appears because it replaces the 
hydroxyl group, and the carbonate peak at wavenumber of $1530-1550 \mathrm{~cm}^{-1}$ was a type B apatite, which is a carbonate group that replaces the phosphate position. Based on Fig. 8.a, it can be seen that for groups of rats 3 to 9 weeks since ovariectomy (TO3 to TO9), they had more type B apatite groups compared to type A apatite. In the TO9 group clearly the highest type B apatite was evident. This means that in the TO9 group more phosphates were replaced by carbonates. The carbonate peak was at wavenumber $1530-1550 \mathrm{~cm}^{-1}$ and showed a greater growth of type B apatite in the ovariectomy group of rats. In the TO9 group the carbonate group intensity was relatively the largest compared to the other groups. This means that the longer the time after the ovariectomy rats, the more the phosphate group was replaced by the carbonate group, and this study occurred in the $9^{\text {th }}$ week since the rat was ovariectomized. This result was supported by the analysis of calcium and phosphorus minerals that are already under normal conditions.

Nano-calcium phosphate diet for osteoporosis rats is shown in Fig. 8.b-d. The figure shows that 19 weeks of dieting, apatite of type A and apatite of type B peaks are almost parallel as in normal bone spectra. The alignment of the two peaks indicates that the growth of phosphate groups was previously replaced by carbonates, so that the administration of nano-calcium phosphate diets for all types gives a better influence on the growth of phosphate in bones.

\subsection{Typical Spectra of Hydroxyl cluster}

Fig. 9-10 showed FTIR spectral samples for hydroxyl groups at wavenumber between $1600-1700 \mathrm{~cm}^{-1}$ and $2800-$ $3400 \mathrm{~cm}^{-1}$. The hydroxyl group for wavenumber between $1600-1700 \mathrm{~cm}^{-1}$ was crystal water. The appearance of crystal water on osteoporosis bones, serves to maintain the shape of the bone so it did not shrink drastically. In groups of ovariectomized rats ranging from TO5 to TO9 (Fig. 9.a), the peak of crystal water at wavenumber $1631 \mathrm{~cm}^{-1}$ tended to be higher than TC and TO3. This showed that the ovariectomy of rats from the fifth week showed a decrease in bone quality. In the group of rats treated with diet, both groups of rats fed the D1, D2 or D3 diets showed curves that changed in a continuous and smooth direction. Fig. 9.b-c, FTIR spectra for crystalline water peaks began to lead continuously with a few low hydroxyl peaks occurring starting in the $12^{\text {th }}$ week since dieting, while the group of rats fed the D3 diet (Fig. 9.d), the crystalline hydroxyl group had disappeared at the $10^{\text {th }}$ week of dieting.

The hydroxyl cluster that appeared at wavenumber between $2800-3400 \mathrm{~cm}^{-1}$, consisted of 3 main peaks that were in the range of wavenumbers $2848 \mathrm{~cm}^{-1}, 2918 \mathrm{~cm}^{-1}$, and $3319 \mathrm{~cm}^{-1}$, which are typical peaks of surface water (Fig. 10). The three peaks were found in the tibia of the TO3-TO9 group as shown in Fig. 10.a. Giving D1, D2 and D3 diets tended to reduce surface water in the range of wavenumber $3319 \mathrm{~cm}^{-1}$. Surface water reduction began at 12 weeks of diet. After 19 weeks the surface water reduction diet was seen increasingly clearly as shown in Fig. 10.b-d. Two other hydroxyl clusters that were in the range of wavenumber $2848 \mathrm{~cm}^{-1}$ and $2918 \mathrm{~cm}^{-1}$ still appeared but the intensity was decreased. The biggest decrease occurred in the group of rats at given a diet for 19 weeks. This indicates, the diet provided an influence in bone repair. 


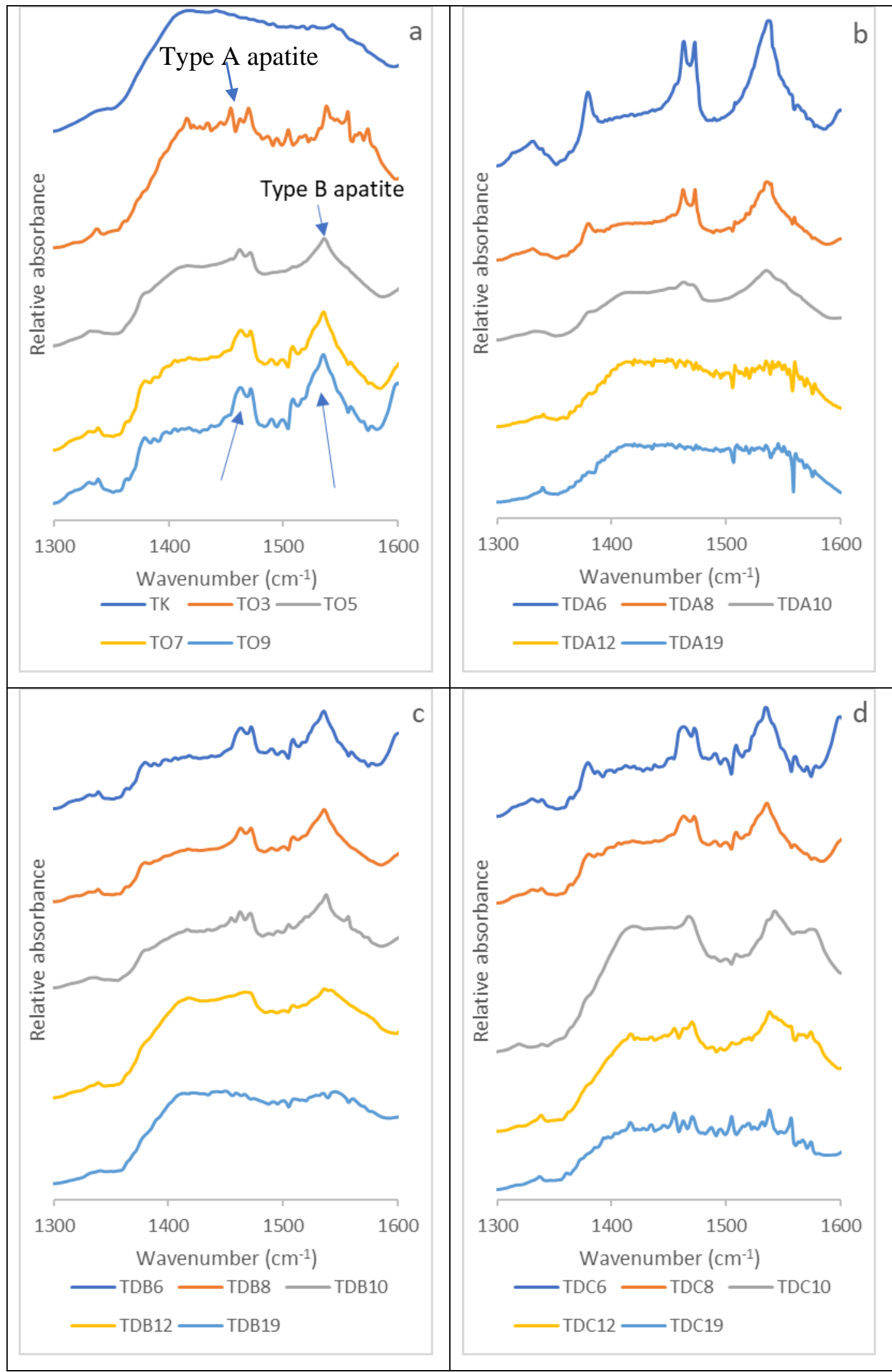

Figure 8: Footage of FTIR results for the carbonate group from tibia at $1300-1600 \mathrm{~cm}^{-1}$ wavenumber. 


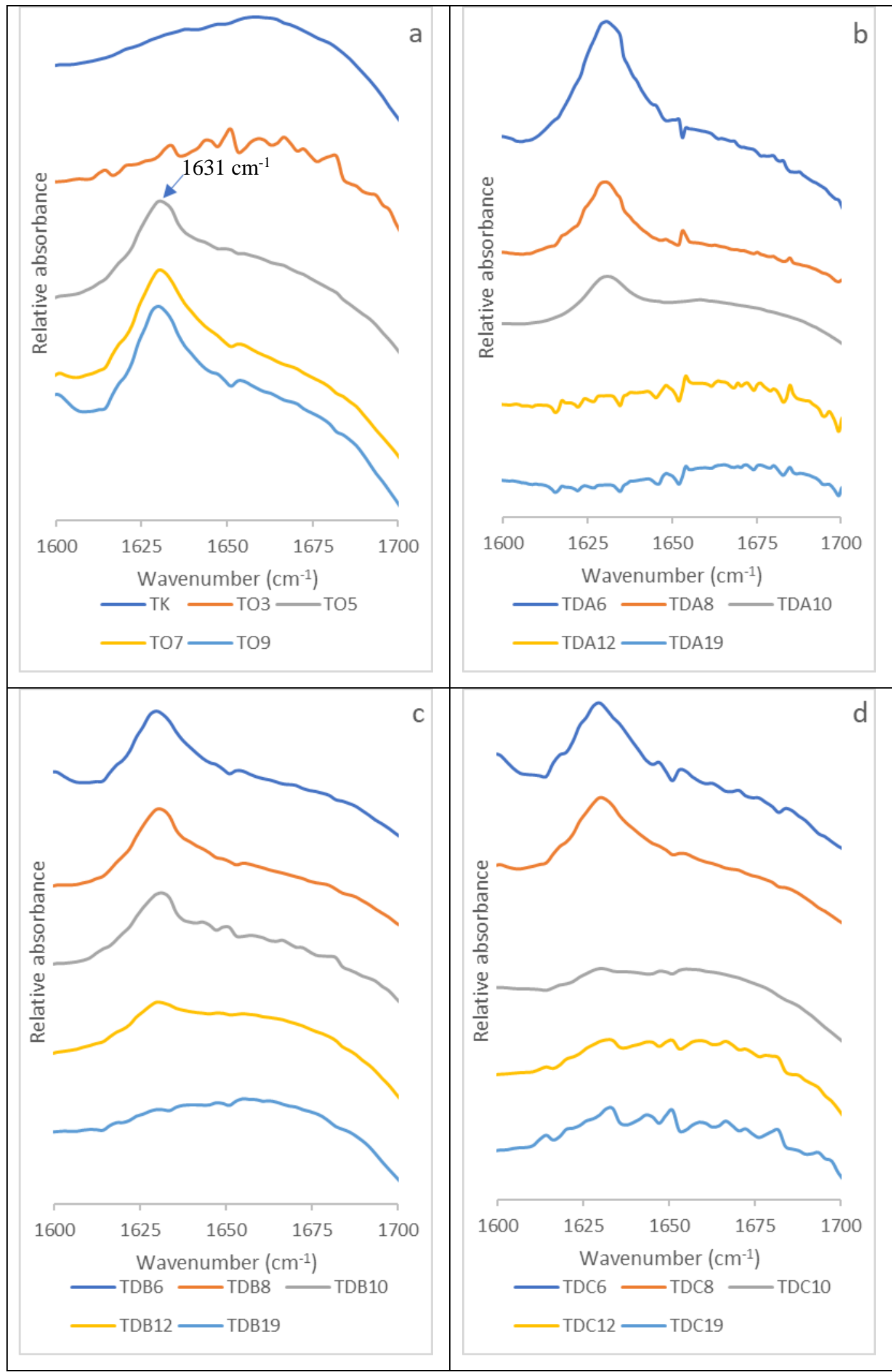

Figure 9: Footage of FTIR results for the hydroxyl group from tibia at $1600-1700 \mathrm{~cm}^{-1}$ wavenumber. 


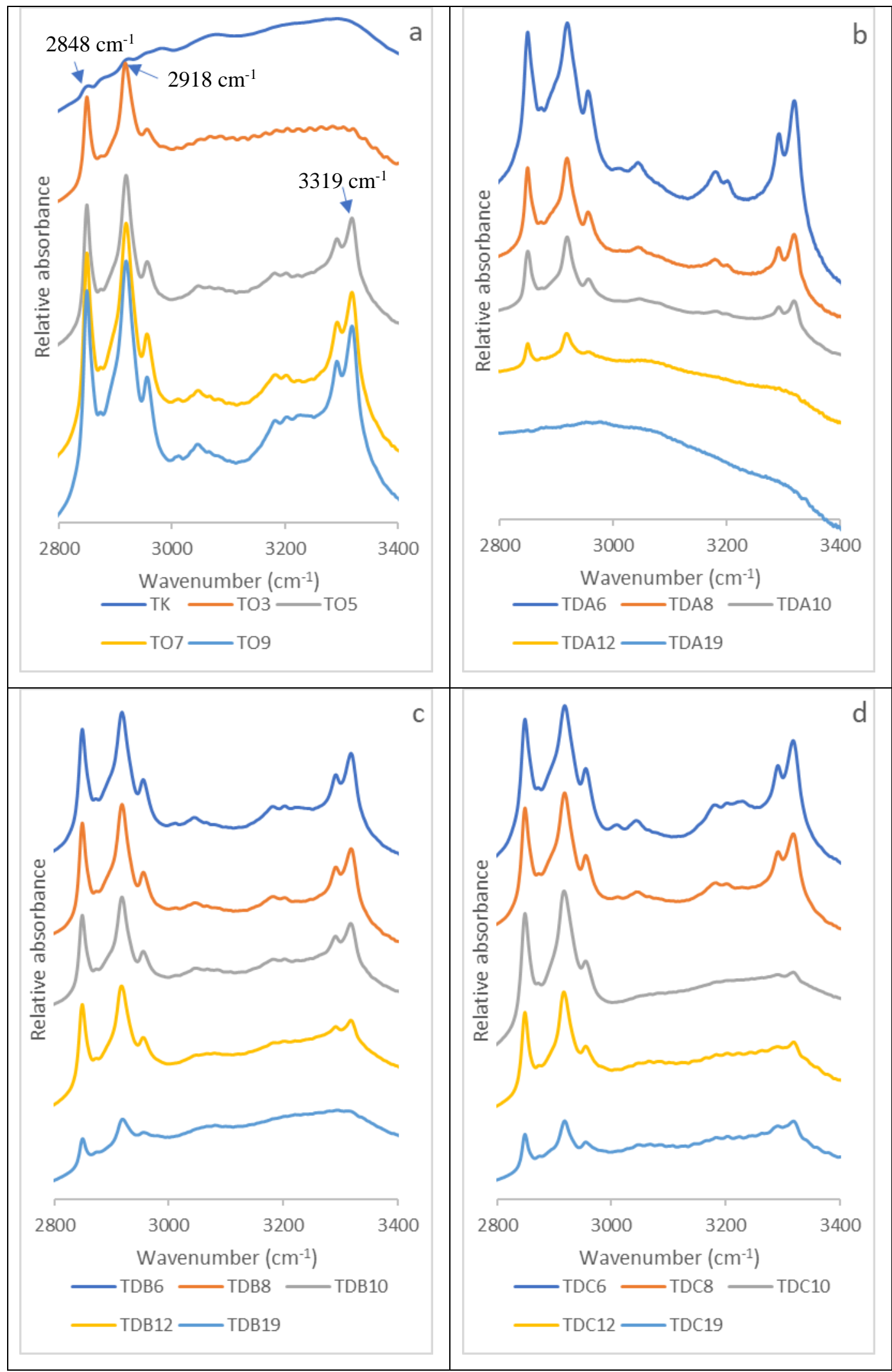

Figure 10: Footage of FTIR results for the hydroxyl group from tibia at $2800-3400 \mathrm{~cm}^{-1}$ wavenumber.

This research still has some limitations including the unknown effect of excess mineral consumption from the D3 diet, so it is necessary to measure mineral uptake and mineral measurements wasted through feces or urine. 


\section{CONCLUSION}

Female white rat (Rattus norvegicus) experienced osteoporosis based on a significant decrease in the mineral content of calcium and phosphorus at $9^{\text {th }}$ week since ovariectomy. This condition is supported by the decrease in phosphate group $v_{4}$ that was replaced by carbonate group and the loss of unstable phosphate in vibrational mode of stretching symmetry $v_{l}$, besides that there was an increase in crystal water as a result of decreased bone quality. This condition is also supported by the declining value of the splitting function which indicates the presence of an amorphous phase. Amorphous phases that appear indicates that the condition of the bones is more fragile.

Nano-calcium phosphate diet given to postovariectomy osteoporosis rats provided an optimal response to the improvement of tibial bone minerals, for nano-calcium phosphate that was added at least $1.5 \mathrm{x}$ the normal requirement (D2). Giving a diet of D2 and D3 for 19 weeks for postovariectomy osteoporosis rats, causing mineral calcium and phosphorus content was higher than normal rats, while magnesium content fluctuates. The increase in calcium and phosphorus minerals in tibia given the $\mathrm{D} 2$ diet were $2.72 \% \mathrm{w} / \mathrm{w} \mathrm{Ca}$ and $12.95 \% \mathrm{w} / \mathrm{w} \mathrm{P}$ respectively, while the increase in calcium and phosphorus minerals in the tibia fed the D3 diet was $22.92 \% \mathrm{w} / \mathrm{w} \mathrm{Ca}$ and $29.11 \% \mathrm{w} / \mathrm{w} \mathrm{P}$ respectively. Of the three types of diets given, the D2 diet was more recommended, because the D1 diet had not been able to meet the mineral needs of the bones, while the D3 diet was over doses of the mineral content.

\section{ACKNOWLEDGEMENT}

This research is supported financially by "Hibah TADOK University of Indonesia" through letter of decree No. 1331/UN2.R3.1/HKP.05.00/2018.

\section{REFERENCES}

[1] Temmerman A, Thor A, "Controlled, multicentre study to evaluate the clinical outcome of implant treatment in women over 60 years of age with osteoporosis/osteopenia: 1-year results", Clinical Oral Implants Research, vol. 00, pp. 1-8, 2016.

[2] Morris HA, Eastell R, Jorgensen NR, Cavalier E, Vasikaran S, Chubb SAP, et al., "Clinical usefulness of bone turnover marker concentrations in osteoporosis", Clinica Chimica Acta, vol. 467, pp. 34-41, 2017.

[3] Lin HH, Huang CY, Hwang LC, "Association between metabolic syndrome and osteoporosis in Taiwanese middleaged and elderly participants", Archives of Osteoporosis, vol. 13, no. 48, pp. 1-7, 2018.

[4] Curtis EM, Moon RJ, Harvey NC, Cooper C, "Reprint of: The impact of fragility fracture and approaches to osteoporosis risk assessment worldwide", Bone, vol. 104, pp. 29-38, 2017.

[5] Wilson DJ, "Osteoporosis and sport", European Journal of Radiology, vol. 110, pp. 169-174, 2019.

[6] Maïmoun L, Ben Bouallègue F, Gelis A, Aouinti S, Mura T, Philibert P, et al., "Periostin and sclerostin levels in individuals with spinal cord injury and their relationship with bone mass, bone turnover, fracture and osteoporosis status", Bone, vol. 127, pp. 612-619, 2019.

[7] Rivadeneira F, Mäkitie O, "Osteoporosis and Bone Mass Disorders: From Gene Pathways to Treatments", Trends in Endocrinology \& Metabolism, vol. 27, no. 5, pp. 262-281, 2016.

[8] Trajanoska K, Rivadeneira F, "The genetic architecture of osteoporosis and fracture risk", Bone, vol. 126, pp. 2-10, 2019.

[9] Adler RA, "Update on osteoporosis in men", Best Practice \& Research Clinical Endocrinology \& Metabolism, vol. 32, no. 5, pp. 759-772, 2018.

[10] Fung TT, Meyer HE, Willett WC, Feskanich D, "Association between Diet Quality Scores and Risk of Hip Fracture in Postmenopausal Women and Men Aged 50 Years and Older", Journal of the Academy of Nutrition and Dietetics, vol. 118, no. 12, pp. 2269-2279, 2018.

[11] Prior JC, Langsetmo L, Lentle BC, Berger C, Goltzman D, Kovacs CS, et al., "Ten-year incident osteoporosisrelated fractures in the population-based Canadian Multicentre Osteoporosis Study - Comparing site and age-specific risks in women and men", Bone, vol. 71, pp. 237-243. 2015.

[12] Rozenberg S, Vandromme J, "Attitudes to the prescription of menopause hormone therapy for vasomotor symptoms and osteoporosis for patients of different ages: A survey of gynecologists in Belgium", Maturitas, vol. 128, pp. 6063, 2019.

[13] Ahmadieh H, Basho A, Chehade A, Al Mallah A, Dakour A, "Perception of peri-menopausal and postmenopausal Lebanese women on osteoporosis: A cross-sectional study", Journal of Clinical \& Translational Endocrinology, vol. 14, pp. 19-24, 2018.

[14] Sapir-Koren R, Livshits G, "Postmenopausal osteoporosis in rheumatoid arthritis: The estrogen deficiency-immune mechanisms link", Bone, vol. 103, pp. 102-115, 2017.

[15] Kendler DL, Marin F, Zerbini CAF, Russo LA, Greenspan SL, Zikan V, et al., "Effects of teriparatide and risedronate on new fractures in post-menopausal women with severe osteoporosis (VERO): a multicentre, doubleblind, double-dummy, randomised controlled trial", The Lancet, vol. 391, no. 10117, pp. 230-40, 2018. 
[16] Roberts BC, Giorgi M, Oliviero S, Wang N, Boudiffa M, Dall'Ara E, "The longitudinal effects of ovariectomy on the morphometric, densitometric and mechanical properties in the murine tibia: A comparison between two rat strains", Bone, vol. 127, pp. 260-270, 2019.

[17] Iwasa T, Matsuzaki T, Yano K, Irahara M, "The effects of ovariectomy and lifelong high-fat diet consumption on body weight, appetite, and lifespan in female rats", Hormones and Behavior, vol. 97, pp. 25-30, 2018.

[18] Chakuleska L, Michailova R, Shkondrov A, Manov V, Zlateva-Panayotova N, Marinov G, et al, "Bone protective effects of purified extract from Ruscus aculeatus on ovariectomy-induced osteoporosis in rats", Food and Chemical Toxicology, vol. 132, 1-12, 2019.

[19] Sharma D, Larriera AI, Palacio-Mancheno PE, Gatti V, Fritton JC, Bromage TG, et al, "The effects of estrogen deficiency on cortical bone microporosity and mineralization", Bone, vol. 110, pp. 1-10, 2018.

[20] Chu X, Guarraci FA, Ågmo A, "Sociosexual behaviors and reproductive success of rats (Rattus norvegicus) in a seminatural environment", Physiology \& Behavior, vol. 151, pp. 46-54, 2015.

[21] Yuan F, Peng W, Yang C, Zheng J, "Teriparatide versus bisphosphonates for treatment of postmenopausal osteoporosis: A meta-analysis", International Journal of Surgery, vol. 66, pp. 1-11, 2019.

[22] Kamimura M, Ikegami S, Mukaiyama K, Koiwai H, Nakamura Y, Taguchi A, et al, "Additive effects of eldecalcitol in poorly responding long-term bisphosphonate treatment for osteoporosis", Osteoporosis and Sarcopenia, vol. 5, no. 2, pp. 57-61, 2019.

[23] Kim J, Jang SB, Kim SW, Oh JK, Kim TH, "Clinical effect of early bisphosphonate treatment for pyogenic vertebral osteomyelitis with osteoporosis: An analysis by the Cox proportional hazard model", The Spine Journal, vol. 19, no. 3, pp. 418-429, 2019.

[24] Romualdo PC, Cunha NBFF, Leoni GB, Sousa-Neto MD, Consolaro A, Queiroz AM, "The effect of ovariectomy and 2 antiresorptive therapeutic agents on bone response in rats: A 3-dimensional imaging analysis", Oral Surgery, Oral Medicine, Oral Pathology and Oral Radiology, vol. 126, pp. 218-225, 2018.

[25] Cosman F, "Parathyroid hormone and abaloparatide treatment for osteoporosis", Current Opinion in Endocrine and Metabolic Research, vol. 3, pp. 61-67, 2018.

[26] Elkomy MM, Elsaid FG, "Anti-osteoporotic effect of medical herbs and calcium supplementation on ovariectomied rats", The Journal of Basic and Applied Zoology, vol. 72, pp. 81-88, 2015.

[27] Giaze TR, Shuid AN, Soelaiman IN, Muhammad N, Mohamed N, "Low dose Marantodes pumilum leaf and roots extracts preserved bone structure in ovariectomized rats", International Journal of Osteoporosis and Metabolic Disorders, vol. 10, no. 1, pp. 1-9, 2017.

[28] Sabudin S, Marzuke MA, Hussin Z, "Effect of mechanical properties on porous calcium phosphate scaffold", Material Today: Proceedings, vol. 16, pp. 1680-1685, 2019.

[29] PT. Feedmill Indonesia, Detail pakan ikan apung dari Malindo, www. Indonetwork.co.id, Indonesia, 2014.

[30] Astuti DA, Diet untuk hewan model, IPB Press Bogor, Indonesia, 2015.

[31] Mulyaningsih NN, Juwono AL, Soejoko DS, Astuti DA, "Synthesis and Characterization of Nano-Sized $\mathrm{CaCO}_{3}$ in Purified Diet", AIP Conference Proceedings, vol. 1862, pp. 1-5, 2017.

[32] Cabeza M, Feijoo I, Merino P, Pena G, Pérez MC, Cruz S, et al, "Effect of high energy ball milling on the morphology, microstructure and properties of nano-sized $\mathrm{TiC}$ particle-reinforced $6005 \mathrm{~A}$ aluminium alloy matrix composite", Powder Technology, vol. 321, pp. 31-43, 2017.

[33] Oetama EJ, Juwono AL, Soejoko DS, Astuti DA, "The impact of dietary hydrolyzed collagen on bone's calcium deficiency of Rattus norvegicus", IOP Conference Series Earth and Environmental Science, vol. 187, no. 1, pp. 1-7, 2018.

[34] Association of Analytical Communities, Official Method of Analysis $18^{\text {th }}$ Edition, AOAC International, Gaithersburg (USA), 2007.

[35] Alvarez LP, Rodriguez-Navarro AB, Romanek CHS, Gaines KF, Congdon YJ, "Quantitative analysis of bone mineral using FTIR", Macla, vol. 6, pp. 45-47, 2006.

[36] Figueiredo MM, Gamelas JAF, Martins AG, "Characterization of Bone and Bone-Based Graft Materials Using FTIR Spectroscopy", Infrared Spectroscopy - Life and Biomedical Sciences, pp. 315-338, 2012.

[37] Reyes-Gasga J, Martínez-Piñeiro EL, Rodríguez-Álvarez G, Tiznado-Orozco GE, García-García R, Brès EF, "XRD and FTIR crystallinity indices in sound human tooth enamel and synthetic hydroxyapatite", Material Science Engineering C, vol. 33, no. 8, pp. 4568-4574, 2013.

[38] Bohic S, Rey C, Legrand A, Sfihi H, Rohanizadeh R, Martel C, Barbier A, Daculsi G, "Characterization of the trabecular rat bone mineral: effect of ovariectomy and biphosphonate treatment", Bone, vol. 26, pp. 341-348, 2000.

[39] Erem S, Atfi A, Razzaque MS, "Anabolic effects of vitamin D and magnesium in aging bone", Journal Steroid Biochemistry Molecular Biology, vol. 193, pp. 1-8, 2019.

[40] Rey C, Shimizu M, Collins B, Glimcher MJ, "Resolution-enhanced fourier transform infrared spectroscopy study of the environment of phosphate ion in the early deposits of a solid phase of calcium phosphate in bone and enamel and their evolution with age: 2 . Investigations in the $v_{3} \mathrm{PO}_{4}$ domain", Calcified Tissue International, vol. 49, pp. 383$388,1991$. 